\title{
PREVALENCE AND DISTRIBUTION OF SELECTED DENTAL ANOMALIES IN NAJRAN CITY OF SAUDI ARABIA
}

\author{
Ahmed Mohammed Alassiry*
}

\begin{abstract}
Background: Dental anomalies are significant deviation in the anatomy, morphology, number, dimension and eruption pattern of teeth. Their effects can range from being negligible to having extreme consequences on the stomatognathic system.
\end{abstract}

Objective: The aim of this study was to evaluate the prevalence, gender and arch distribution of selected dental anomalies in the population of Najran city of Saudi Arabia. It also aims to compare the dental anomalies in Najran population with the other population of Saudi Arabia and other parts of world.

Material and Methods: The study sample included 572 patients (196 male and 376 females) between the ages of $8-34$ years, who visited the orthodontic department in dental college clinic of Najran university and Najran University hospital in the year 2019. The data was collected through clinical examination, dental cast evaluation and digital panoramic radiographic assessment. Seven dental anomalies including hypodontia, impaction (excluding third molars), supernumerary teeth, peg shaped laterals, hypercementosis, taurodontism and transposition were evaluated in the study.

Results: The most prevalent dental anomaly was found to be transposition (29.4\%) followed by impaction (23.4\%), hypodontia (21.2\%), peg shaped lateral incisor $(8.4 \%)$ and hypercementosis (3.1\%). Only hypodontia showed statistically significant difference between males and females. Taurodontism and supernumerary teeth were the least prevalent anomaly at $1.4 \%$.

Conclusion: Results of the study provide insights into the prevalence of dental anomalies in Najran population of Saudi Arabia. This data can be useful both epidemiologically and clinically to combat the problem of dental anomaly.

KEYWORDS: Dental anomaly, prevalence, Cross-sectional, Saudi Arabia, Najran

* Associate Professor, Department of Preventive Dental Sciences, Dean of Faculty of Dentistry, Najran University, Saudi Arabia. 


\section{INTRODUCTION}

Tooth development is a complex yet predetermined process. Any deviation from the normal, standard or expected microscopic events in the tooth developmental process can lead to a dental anomaly. Anomalies, aberrations or abnormalities arising in dental science can be due to the variation in the size, shape, number, structure and position of the tooth. ${ }^{1}$ An abnormal deviation in the tooth size can cause microdontia or macrodontia. An anomaly in the shape can lead to fusion, dens invaginatus, dens evaginatus, talon cusp, gemination, dilaceration, taurodontism or concrescence. Any aberrations in the number of teeth can result in hyperdontia, hypodontia or oligodontia. Similarly, any structural defects during development can give rise to amelogenesis imperfecta, dentinogenesis imperfecta or dentin dysplasia. Positional variations from the normal can entail to impaction, rotation or ectopic eruption. All these encompass the broad terminology of dental anomaly which interestingly, is common observation during routine dental examination.

The etiology of dental anomalies is no different form the other pathologies of the oro-dental complex. They are multifactorial and depend upon multiple influences affected by genetic, environmental and pathological factors. ${ }^{2-5}$ These factors can affect the pre-natal, intra-natal and post-natal development of teeth involving both the deciduous and permanent dentition. ${ }^{6}$ The genetic factors involve the genes encoding for the morphodiffrentiation and histodifferentiation during odontogenesis. Aberrations can also be inherited through genes, their mutation and atavism. ${ }^{7}$ Environmental factors like metabolism, physical or chemical insults or other biological factors can adversely affect the development of tooth. ${ }^{8-9}$ These anomalies can present themselves as a local deformity restricted to oro-facial region or can be a part of any systemic illness or syndromes. Many research have shown that genetic predisposition plays an important role in manifestation of dental anomalies. ${ }^{10}$ Hence, the consequences are acute and enormous on the affected dentition.

Dental anomalies can manifest in a single tooth, multiple teeth, either of the arches or both. Some are asymptomatic and others can have profound clinical outcomes on the overall well-being of the individual. Dental anomalies per se can lead to an array of problems causing malocclusion, periodontal breakdown, occlusal interferences, attrition and increased susceptibility to caries. It can also lead to compromised esthetics, archlength problems, temporomandibular joint pain and dysfunction. Such anomalies can also affect the speech and mastication. Thus it entangles all the three aspects of dentition i.e. the function, esthetics and stability. With the concomitant presence of these anomalies, it becomes difficult to perform routine dental procedures like root canal treatment and extractions. Certain anomalies are peculiar of some genetic or syndromic problems of the craniofacial region. Timely and accurate identification of such anomalies can lead formulation of effective and robust treatment plans. Meticulous clinical examination and radiographs are useful in the detection, diagnosis and differential diagnosis of these dental anomalies. ${ }^{11-13}$

Although many studies have been performed to assess the prevalence and distribution of dental anomalies in the Saudi population and other parts of the world, most of them have provided with inconsistent, discordant and heterogeneous results owning to the vivid genetic constitution of the population. Considering the epidemiology, it is pertinent to understand that dental anomalies have a huge variation in occurrence, distribution and prevalence throughout the globe as concluded by many research performed on the different population of the world. This can be attributed to the geographic diversity, ethnicity, sample selection methods, sample size and diagnostic criteria of the 
study. ${ }^{14}$ Since, genetic component is involved in the etiology of these anomalies, having information about the prevalence and degree of expression in a particular population can provide insight on the phylogenetic and genetic makeup of it. ${ }^{15}$ This data can also be valuable in evaluating the differences between other population groups, ethnicity or races. Therefore, in the contemporary times, many researchers are focussing on the sub-groups of the population and races rather than evaluating the whole population for the similar clinical problem.

Walking on the similar lines, this study was devised to study a smaller population from Saudi Arabia. The aim of this study was to evaluate the prevalence and distribution of selected dental anomalies in the population of Najran city of Saudi Arabia. The study also assessed the gender-wise differences and arch variation of the selected dental anomalies in Najran population. Additionally, the study aimed to compare the dental anomalies in Najran population with the other population of Saudi Arabia and world. The study intends to provide subgroup population insight about the comprehension of dental anomalies which can aid in their proper diagnosis and effective clinical management.

\section{MATERIAL AND METHODS}

This was a descriptive, cross-sectional and retrospective study in which 572 Saudi Arabian subjects (196 males and 376 females) from Najran city were evaluated for dental anomalies. The subjects ranged from 8-34 years of age who visited the orthodontic department in dental college clinic of Najran university and Najran University hospital over a period of one year from January 2019 to December 2019. The data of the study was collected on the basis of through clinical examination, dental cast evaluation and digital panoramic radiographic assessment of the involved subjects. Only those subjects with the record of these three assessments were included in the study.
The subjects with following findings were excluded from the study

1. Any syndromic patient which can predispose to dental anomalies like Down syndrome, cleft lip and palate, cleidocranial dysplasia etc.

2. Any history of pre-existing systemic diseases

3. Any history of trauma or fracture of the jaws which might have affected the normal growth of the dentition.

4. Any history of tooth extraction or orthodontic treatment.

5. Missing or incomplete dental records.

6. Distorted panoramic radiographs with poor quality and visibility.

Informed consent was taken from each patient to use their data for research purposes. The study protocol was approved by Najran University Ethical Committee. The records of each subject (clinical findings, dental cast and panoramic radiograph) were assessed for the following dental anomalies:

1. Shape anomalies (peg shaped laterals and taurodontism)

2. Number anomalies (hypodontia and supernumerary teeth)

3. Positional anomalies (transposition and impaction)

4. Structural anomaly (hypercementosis).

A single investigator evaluated the records of the total sample to diagnose and tabulate the dental anomalies. This was done to avoid variation arising due to difference in personal interpretations by multiple examiners. The panoramic radiographs were screened at optimum lighting conditions and standard screen resolutions. The complete data was collected and tabulated in Excel (Version:2003, Microsoft, Redmond, USA). The data was then statistically analysed using SPSS, Version 20 
(IBM Corp., Armonk, New York, USA). Chi square test was used for descriptive analysis and frequency values. The level of significance was set at $95 \%$ confidence interval. A p-value of $<0.05$ was considered to be statistically significant. Around 100 records were randomly selected form the sample and were re-evaluated by the same investigator after a two-week interval to assess the agreement on diagnosis. Kappa statistics was used to evaluate the error of identification of each dental anomaly.

\section{RESULTS}

In this study, a total of 572 subjects were evaluated belonging to the Najran population of Saudi Arabia. Among them, males were 196 (34.3\%) and females were $376(65.7 \%)$ in number and percentage respectively. Table 1 shows the prevalence and gender-wise distribution of 7 selected dental anomalies evaluated in this study. The most prevalent dental anomaly was found to be transposition (29.4\%) followed by impaction (excluding third molars) (23.4\%), hypodontia (21.2\%), peg shaped lateral incisor (8.4\%) and hypercementosis $(3.1 \%)$. Of the selected dental anomalies studied, only hypodontia has shown statistically significant difference between males and females $(\mathrm{p}<0.05)$. The other dental anomalies have shown no statistically significant difference it respect to gender as shown in Table 1. Figure 1 shows the gender-wise prevalence of dental anomalies in Najran population. Both males and females show transposition as the most prevalent anomaly with $27 \%$ and $30 \%$ respectively. Supernumerary teeth in males $(1.5 \%)$ and taurodontism in females $(0.8 \%)$ were the least prevalent anomaly. With respect to arch-wise distribution of dental anomalies, only supernumerary teeth and transposition in males, taurodontism in females \& hypercementosis in males and females have shown increased prevalence in the mandibular arch. Most of the other dental anomaly have shown increased prevalence in the maxillary arch as compared to the mandibular arch as shown in Table 2. Kappa value ranged from 0.867 to 1 , which indicates perfect agreement between the first and the second evaluations of the dental records.

TABLE (1) Prevalence and gender-wise distribution of Dental Anomalies in Najran population

\begin{tabular}{|l|c|c|c|c|}
\hline \multicolumn{1}{|c|}{ Developmental Anomaly } & $\begin{array}{c}\text { Prevalence } \\
\text { n (\%) }\end{array}$ & N $572(\%)$ & $\begin{array}{c}\text { Male } \\
\text { Gender } \\
\text { n (\%) }\end{array}$ & \multirow{2}{*}{$\begin{array}{c}\text { Female } \\
\mathrm{n}=376(\%)\end{array}$} \\
\hline Pypalue \\
\hline Impaction & $121(21.2)$ & $29(14.8)$ & $92(24.5)$ & $0.019 *$ \\
\hline Supernumerary teeth & $134(23.4)$ & $47(24)$ & $87(23.13)$ & 0.139 \\
\hline Peg-shaped Lateral Incisor & $08(1.4)$ & $03(1.5)$ & $05(1.3)$ & 0.315 \\
\hline Hypercementosis & $48(8.4)$ & $13(6.6)$ & $35(9.31)$ & 0.497 \\
\hline Taurodontism & $18(3.1)$ & $07(3.6)$ & $11(2.92)$ & 0.515 \\
\hline Transposition & $08(1.4)$ & $05(2.6)$ & $03(0.8)$ & 0.388 \\
\hline
\end{tabular}

* statistical significant $p<0.05$ 


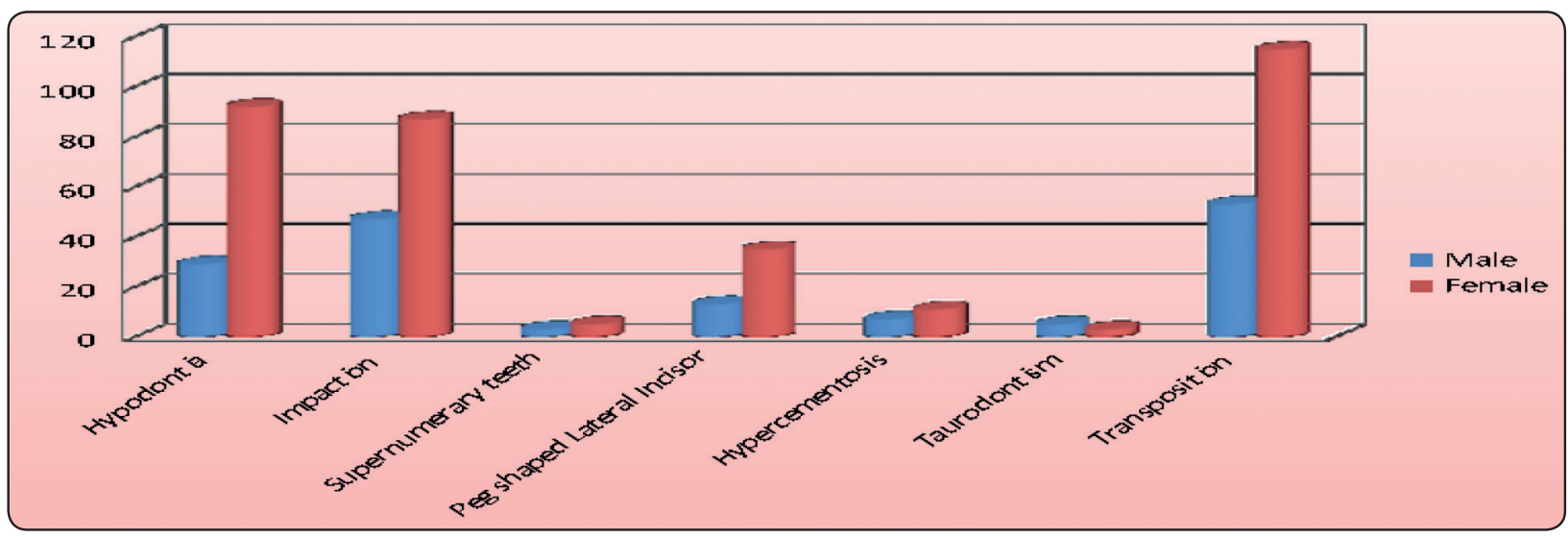

Fig. (1) Gender wise prevalence of Dental Anomalies in Najran population.

TABLE (2) Arch-wise gender distribution of selected Dental Anomalies in Najran population.

\begin{tabular}{|c|c|c|c|}
\hline $\begin{array}{c}\text { Developmen- } \\
\text { tal Anomaly }\end{array}$ & $\begin{array}{c}\text { Gender } \\
\text { distribution } \\
\text { (n) }\end{array}$ & $\begin{array}{c}\text { Maxillary } \\
\text { arch } \\
\text { n }(\%) \\
\end{array}$ & $\begin{array}{c}\text { Mandibular } \\
\text { Arch } \\
\text { n }(\%) \\
\end{array}$ \\
\hline \multirow{2}{*}{ Hypodontia } & Male (29) & $\begin{array}{c}25 \\
(86 \%)\end{array}$ & $\begin{array}{c}04 \\
(14 \%)\end{array}$ \\
\hline & Female (91) & $\begin{array}{c}51 \\
(56 \%) \\
\end{array}$ & $\begin{array}{c}41 \\
(44 \%) \\
\end{array}$ \\
\hline \multirow{2}{*}{ Impaction } & Male (47) & $\begin{array}{c}28 \\
(59.5 \%) \\
\end{array}$ & $\begin{array}{c}19 \\
(40.5 \%) \\
\end{array}$ \\
\hline & Female (87) & $\begin{array}{c}68 \\
(78 \%)\end{array}$ & $\begin{array}{c}19 \\
(22 \%)\end{array}$ \\
\hline \multirow{2}{*}{$\begin{array}{l}\text { Supernumer- } \\
\text { ary teeth }\end{array}$} & Male (03) & $\begin{array}{c}01 \\
(33.3 \%)\end{array}$ & $\begin{array}{c}02 \\
(66 \%)\end{array}$ \\
\hline & Female (05) & $\begin{array}{c}04 \\
(80 \%) \\
\end{array}$ & $\begin{array}{c}01 \\
(20 \%) \\
\end{array}$ \\
\hline \multirow{2}{*}{$\begin{array}{l}\text { Peg shaped } \\
\text { Lateral Incisor }\end{array}$} & Male (13) & $\begin{array}{c}13 \\
(100 \%) \\
\end{array}$ & $\begin{array}{c}00 \\
(0 \%)\end{array}$ \\
\hline & Female (35) & $\begin{array}{c}35 \\
(100 \%)\end{array}$ & $\begin{array}{c}00 \\
(0 \%)\end{array}$ \\
\hline \multirow{2}{*}{$\begin{array}{l}\text { Hypercemen- } \\
\text { tosis }\end{array}$} & Male (07) & $\begin{array}{c}02 \\
(28.5 \%)\end{array}$ & $\begin{array}{c}05 \\
(71.4 \%)\end{array}$ \\
\hline & Female (11) & $\begin{array}{c}01 \\
(10 \%)\end{array}$ & $\begin{array}{c}10 \\
(90 \%)\end{array}$ \\
\hline \multirow{2}{*}{ Taurodontism } & Male (05) & $\begin{array}{c}03 \\
(60 \%)\end{array}$ & $\begin{array}{c}02 \\
(40 \%)\end{array}$ \\
\hline & Female (03) & $\begin{array}{c}00 \\
(0 \%)\end{array}$ & $\begin{array}{c}03 \\
(100 \%)\end{array}$ \\
\hline \multirow{2}{*}{ Transposition } & Male (53) & $\begin{array}{c}23 \\
(43 \%)\end{array}$ & $\begin{array}{c}30 \\
(57 \%)\end{array}$ \\
\hline & Female (115) & $\begin{array}{c}58 \\
(50.5 \%)\end{array}$ & $\begin{array}{c}57 \\
(49.5 \%)\end{array}$ \\
\hline
\end{tabular}

\section{DISCUSSION}

Dental anomalies are frequently encountered in pediatric or orthodontic dental offices. Often their treatment requires multidisciplinary approach involving orthodontic, prosthodontics, restorative and surgical intervention. This escalates the time and expenses involved in the treatment, becoming a challenge for the clinician and burden on the family's financial budget. ${ }^{16}$ The prevalence of these dental anomalies is highly variable due to the presence of various racial and ethnic groups. ${ }^{17}$ This study has been done specifically on the Najran inhabitants of Saudi Arabia to evaluate the prevalence and distribution of different dental anomalies existing in the population. Although many studies have been done in the past involving the other population groups of Saudi Arabia, the aim of this study was to provide current and contemporary insights into problem of dental anomaly in Najran city of Saudi Arabia.

Transposition is the ectopic eruption of tooth not in its normal position. It is the positional interchange of two neighboring teeth and especially of their roots, or the development or eruption of the tooth in a position normally occupied by a non-neighboring tooth. ${ }^{18}$ Tooth transposition is commonly observed in maxillary canine-first premolar and mandibular lateral incisor-canine region. ${ }^{19-20}$ Etiological 
factors leading to transposition include genetics, interchange of developing tooth buds, altered eruption, the presence of retained primary teeth or pathologies, high bone density and trauma..$^{21-22}$ In this study, the prevalence of transposition has been found to be $29.4 \%$ which is much higher and in contradiction to other studies performed in Saudi and non-Saudi populations. In studies performed on Saudi population, Alswayyed reported a small prevalence of $0.33 \%$ among orthodontic patients from Riyadh. ${ }^{23} \mathrm{Al}-\mathrm{Jabaa}{ }^{24}$ reported a prevalence of $4.7 \%$ from King Saud University, Afify ${ }^{13}$ reported a prevalence of $0.7 \%$ from the western region of Saudi Arabia, Vani ${ }^{25}$ reported a prevalence of $0.3 \%$ from Jazan and Yassin ${ }^{11}$ reported a prevalence of 2.3\% among the Abha population of Saudi Arabia. In a meta-analysis conducted by Papadopoulos MA et $\mathrm{al}^{26}$, the average prevalence of tooth transposition was found to be $0.33 \%$. In general population, the prevalence of transposition has been consistently low. It was reported to be $0.09 \%$ in $\mathrm{Greece}^{27}, 0.13 \%$ in Germany ${ }^{28}, 0.38 \%$ in Turkey ${ }^{29}, 0.40 \%$ in India ${ }^{21}$, $0.66 \%$ in $\mathrm{Nepal}^{30}$ and $1.4 \%$ in Nigeria. ${ }^{31}$

Considering the gender-wise distribution of transposition, no statistically significant difference was found in this study. This is in accordance with the finding of Papadopoulos MA et $\mathrm{al}^{26}$ who found no statistically significant difference in the prevalence of transposition between males and females. Similar findings were reported by Ghassan et al ${ }^{32}$, Kazanci et $\mathrm{al}^{33}$ and Alswayyed ${ }^{23}$ in their study on Sudanese, Turkish and Riyadh population respectively. In terms of location, transposition was more in males in the maxillary arch (57\%) than in the mandibular $\operatorname{arch}(43 \%)$. In females the distribution was almost equal in the maxillary (50.5\%) and mandibular $(49.5 \%)$ arches. Papadopoulos MA et $\mathrm{al}^{26}$ also reported a higher occurrence of transposition in the maxillary arch as compared to the mandibular arch. It is attributed to the lower bone density of maxilla which enhance the incidence of tooth transposition and high bone density of the mandible which prevents the phenomenon of transposition. So, transposition is usually a rare phenomenon but found to be most prevalent anomaly in the Najran population. It has no specific gender predilection but seen more commonly in the maxillary arch.

An impacted tooth unerupts after complete root development. It can be obstructed in its path of eruption by an adjacent tooth, bone or soft tissue. According to Bass, impacted teeth are defined as teeth that remain completely or incompletely embedded in the jawbone or mucosa for more than 2 years following physiological eruption time. ${ }^{34}$ Impaction occurs due to lack of space in the arch, presence of cyst or pathologies, retained primary teeth, supernumerary teeth or any kind of obstruction. Usually third molars are impacted more owing to their late eruption and lack of space in the arch. Subsequently, maxillary canines are are prone to impaction due to their long path of eruption..$^{35-36}$ Impacted teeth can be completely asymptomatic or can can plethora of oro-dental problems. In this study, impacted teeth has been found to be the second most prevalent dental anomaly in the Najran population with a prevalence of $23.4 \%$. In similar studies done on other population groups of Saudi Arabia, the prevalence of impacted teeth has been found to be $52.7 \%$ by Al-Jabaa ${ }^{24}$ from King Saud University, $21.1 \%$ by Alswayyed ${ }^{23}$ among orthodontic patients from Riyadh and $29.1 \%$ by Afify $^{13}$ from the western region of Saudi Arabia. In other part of the world, prevalence of impaction has been reported at $3.74 \%$ in Indian population ${ }^{37}$ and $8.4 \%$ in Norwegian population. ${ }^{38}$ In similar studies done on non-orthodontic population, prevalence has been found to be $8.3 \%$ and $9.9 \%$ by Ezoddini et $\mathrm{al}^{4}$ $\&$ Thongudomporn and Freer ${ }^{39}$ respectively.

In terms of gender, no significant difference was found between males and females in this study. This finding is in accordance with the results of Ghassan et $\mathrm{a}^{32}$ on Sudanese population and Alswayyed ${ }^{23}$ on Riyadh population. In terms of arch distribution, 
impaction was more prevalent in the maxillary arch. In males, impaction was found to be $59.5 \%$ in maxillary arch and $40.5 \%$ in mandibular arch. In females, impaction was $78 \%$ in maxillary arch and $22 \%$ in mandibular arch. In this study, maxillary transposition has been found to be the most prevalent anomaly. Since there is a positional relation between transposition and impaction, it can be the reason for high prevalence of maxillary impaction found in this studied population. In this study, only impaction as a finding was considered. The different class of the tooth or the type of impaction was not taken into consideration. This is one limitation to the findings of the present study. So, in Najran population, impaction is second most prevalent anomaly with no specific gender preponderance but observed more commonly in the maxillary arch.

Hypodontia is the congenital absence of one or few teeth. ${ }^{40}$ Terminology of hypodontia can be refined to congenital missing of less than six teeth. Oligodontia is the congenital missing of six or more teeth. Anodontia is the complete absence of dentition. It arises due to mild dysplastic expression of the ectoderm during the initial stages of tooth development. ${ }^{41-42}$ Genetic research has shown the involvement of MSX, PAX9 and TGFA genes in the etiology of hypodontia. ${ }^{43-44}$ In this study, hypodontia was the third most prevalent anomaly with a prevalence of $21.2 \%$. In studies conducted on other population of Saudi Arabia, Yassin ${ }^{11}$ had reported a prevalence of $4.2 \%$ in Abha population. Similarly Afify $^{13}$ reported a prevalence of $25.7 \%$ from the western region of Saudi Arabia. Al-Jabaa ${ }^{24}$ reported a prevalence of $19.1 \%$ from King Saud University, $2.2 \%$ was reported from Gizan by Salem ${ }^{45}, 5.2 \%$ by Vani $^{25}$ from Jazan, $4 \%$ by Al-Emran ${ }^{46}$ in Saudi males, $9.41 \%$ in Najran by Ghaznawi ${ }^{47}$ and $33.78 \%$ by Alswayyed ${ }^{23}$ among orthodontic patients from Riyadh. In terms of continent, Asia reports the highest prevalence of hypodontia at $16.2 \%$ followed by Europe 15.7\%, North America 7.8\%, Australia 6.4\% and South America 6.3\%. ${ }^{16}$ In general population, low prevalence of $4.6 \%$ and $6.6 \%$ was reported in the Turkey ${ }^{48}$ and Norway ${ }^{38}$ respectively. A prevalence of $7.48 \%$ was reported in $\mathrm{Nepal}^{30}, 10.9 \%$ in India ${ }^{37}$ and $34.8 \%$ in the Iranian population. ${ }^{49}$ Is is watchful to note that the prevalence of hypodontia is increasing as the researches get published. This can be attributed to increase in diagnosis, evolutionary or environmental changes. Usually, the third molars, mandibular premolars and maxillary lateral incisors are the most frequently missing teeth. ${ }^{35}$ Hypodontia can be present with delayed eruption of other teeth, retained primary teeth, ectopic eruptions, taurodontism, peg-shaped lateral incisors and microdontia of other teeth.

In this study, females have shown greater prevalence of hypodontia $(24.5 \%)$ as compared to males $(14.85 \%)$. This finding is in concordance with the findings of Alswayyed ${ }^{23}$ who reported a greater prevalence of hypodontia in females (35.51\%) as compared to males $(32.81 \%)$ among the orthodontic patients from Riyadh. Universally, females are affected more than males in the ration of 3:2. This can be attributed to the biological fact of the presence of smaller jaws in females. Moreover, there is an increase in the number of female patients approaching for orthodontic problems and eventually being diagnosed for hypodontia leading to its increased prevalence in the population. In this study, hypodontia was predominantly present in the maxillary arch in males $(86 \%)$ than mandibular $\operatorname{arch}(14 \%)$. For the females, the difference was not much in the maxillary (56\%) and mandibular (44\%) arches. In other studies performed assessing the predominance of arch in hypodontia, the results have been conflicting and inconclusive. Some studies showed significant difference, some marginally significant difference or insignificant differences in the arches..$^{50-51}$ Concluding, hypodontia is common, usually appearing more in females and may accompany with other dental anomalies. The treatment is comprehensive, expensive and may pose an interdisciplinary challenge. 
Peg-shaped Lateral Incisors teeth have shorter incisal mesio-distal width than the cervical width. They are smaller than the average normal size, or its contralateral homologue or a tooth of the same group from opposing arch. Peg shaped teeth develop from a single lobe instead of four and their occurrence is predominantly genetically determined..$^{52}$ They can be highly unesthetic in appearance and can be associated with certain syndromic conditions. In this study, the prevalence of peg-shaped lateral incisors has been found to be $8.4 \%$. In other population of Saudi Arabia, Salem ${ }^{45}$ reported a prevalence of $0.37 \%$ from Gizan, Vani ${ }^{25}$ reported $0.9 \%$ from Jazan and Al-Emran ${ }^{46}$ reported about $4 \%$ in Saudi males from Riyadh. In general population, prevalence of peg-shaped lateral incisors ranged from $1.3 \%$ in whites, $1.4 \%$ in blacks and $3.1 \%$ in Mongoloids. Hua $\mathrm{F}$ et $\mathrm{al}^{53}$ in their meta-analysis reported an overall prevalence of peg-shaped lateral incisor at $1.8 \%$. In this study, no significant difference was found in the gender-wise distribution of peg-shaped lateral incisors. Hua $\mathrm{F}$ et $\mathrm{a}^{53}$ reported women are 1.35 times more likely than men to have pegshaped lateral incisors. Furthermore in this study, peg-shaped lateral incisors were found only in the maxillary arch, although they have been rarely reported in the mandibular arch too.

Hypercementosis is also known as cementum hyperplasia and is characterized by excessive deposition of cementum on the roots of one or more teeth. ${ }^{54}$ It can affect any tooth but premolars are most frequently affected. Local etiological factors include occlusal forces, trauma and periapical pathologies. It is also associated with systemic factors like Paget's disease, hyperthyroidism, acromegaly, arthritis and vitamin A deficiency. ${ }^{55}$ In this study, prevalence of $3.1 \%$ has been found in the Najran population. This is in accordance with the result published by Patil SR et al who reported a prevalence of $4.82 \%$ in Saudi population. ${ }^{56}$ In general population, the prevalence was found to be $1.3 \%$ in Germany, ${ }^{57}$ $2.4 \%$ in Turkey $^{58}$ and $10.2 \%$ in UAE. ${ }^{59}$ No gender predilection for hypercementosis was found in this study which is in contrast with the findings of Patil SR et $\mathrm{al}^{56}$ who reported increased prevalence of hypercementosis in females. Moreover, mandible was affected more than maxilla in both the males and females by $71.4 \%$ and $90 \%$ respectively. This in in accordance with the findings of Burklein et $\mathrm{al}^{57}$ who reported double prevalence in mandible as compared to maxilla. But this finding of archwise distribution of hypercementosis is in contrast to the study published by Patil SR et $\mathrm{al}^{56}$ who did not observe notable difference between the two arches. Clinically, performing endodontic treatment or extraction of tooth with hypercementosis can be problematic and may require meticulous approach.

Taurodontism is the condition in which the tooth trunk is elongated, floor of the pulp chamber is apically displaced and the roots are proportionally shortened. It occurs due to the failure of Hertwig's epithelial sheath diaphragm to invaginate at the proper horizontal level. The diagnosis of taurodontism is made by subjective radiographic evaluation. ${ }^{60}$ In this study, the prevalence of taurodontism has been found to be $1.4 \%$ with no gender predilection. This is similar to the finding of Yassin who reported a prevalence of $1.4 \%$ in the Abha population of Saudi Arabia. ${ }^{11}$ In other population of Saudi Arabia, it has been reported at $0.1 \%$ in Najran ${ }^{13}, 2.8 \%$ in Jazan $^{25}$ and $8.61 \%$ at King Saud University. ${ }^{24}$ In general population, prevalence was reported at $8 \%$ in Jordan ${ }^{61}, 6.2 \%$ in Norway ${ }^{38}, 0.49 \%$ in $\mathrm{Nepal}^{30}$, $4.1 \%$ in $\mathrm{UAE}^{59}$ and $11.8 \%$ in India. ${ }^{37}$ In this study, the prevalence in males was more in maxilla $(60 \%)$ and in females, it was found in mandible only. Taurodontism is clinically important as it has been associated with several syndromes, abnormalities and pose a challenge in endodontic therapy. Root canal treatment should be performed considering complexity of root canal, canal configuration and additional canal systems in cases of taurodontism. ${ }^{61}$

Supernumerary teeth are additional to the normal series. They can be single or multiple, unior bilateral, impacted or erupted; they may have normal or altered morphology, and may be found 
in both dentitions. Supernumerary tooth, other than genetic causes may also arise either as a result of a dichotomy of the tooth bud, or as a result of local, independent, conditioned hyperactivity of the dental lamina. Most supernumerary teeth are impacted and asymptomatic and diagnosed incidentally during radiographic examinations. ${ }^{62}$ In this study, the prevalence of supernumerary teeth was $1.4 \%$. In other population of Saudi Arabia, it was found to be $0.5 \%$ in $\operatorname{Gizan}^{45}, 1 \%$ in $\mathrm{Jazan}^{25}, 0.3 \%$ in Najran ${ }^{13}$, $0.33 \%$ Riyadh $^{23}, 3.5 \%$ equally from $\mathrm{Abha}^{11}$ and King Saud University. ${ }^{24}$ In general population, prevalence of supernumerary teeth was found to be $2.4 \%$ in India $^{37}, 2.99 \%$ in $\mathrm{Nepal}^{30}$ and $1.8 \%$ in Greek population. ${ }^{63}$ With respect to gender there was no significant difference in this study which is accordance with the findings of Alswayyed ${ }^{23}$ and Ghassan et $\mathrm{al}^{32}$ while in contrast to the results of $\mathrm{Kazanci}^{33}$ which has shown hyperdontia being more common in males as compared to females. Supernumerary teeth often pose esthetic challenge and can cause malocclusion. Extraction of the extra-teeth followed by appropriate orthodontic or prosthodontic intervention is the time tested modality of treating it.

\section{CONCLUSION}

This study was performed to evaluate the prevalence of selected dental anomalies in the residents of Najran city of Saudi Arabia. In this study, transposition was the most prevalent anomaly followed by impaction, with both having no specific gender predilection but were commonly observed in the maxillary arch. Hypodontia was the third most prevalent anomaly with female preponderance and seen more commonly in the maxillary arch. Peg-shaped lateral incisors were found only in the maxillary arch with no gender bias. Hypercementosis was found more in mandible with no gender preference. Taurodontism and supernumerary teeth were the least prevalent dental anomalies found in the Najran population.
A significant part of Najran population presented with dental anomalies. This can be due the interplay of genetic, local and environmental factors which influences odontogenesis. With urbanization, more number of patients are being aware of their dental conditions. This warrants for the need of early diagnosis, intervention and treatment of such dental anomalies. In this study, the sample of females was more than that of males. Since, dental anomalies directly affects the esthetics and females are more concerned about their looks, more dental records were available for females. This can be considered as a limitation of this study. More researches can be performed with equal sample size and emphasis can be laid on specific dental anomalies. Moreover, etiological factors can be studied pertaining to the Saudi population which can assist in establishing preventive measures to restrict or minimize the consequences of a dental anomaly.

\section{REFERENCES}

1. Uslu O, Akcam MO, Evirgen S, Cebeci I. Prevalence of dental anomalies in various malocclusions. Am J Orthod and Dentofacial Orthop. 2009;135:328-335.

2. Jeong KH, Kim D, Song YM, Sung J, Kim YH. Epidemiology and genetics of hypodontia and microdontia: A study of twin families. Angle Orthod. 2014;85: 980-985.

3. Kotsomitis N, Dunne M, Freer T. A genetic aetiology for some common dental anomalies: a pilot twin study. Aust Orthod J. 1996;14(172):8.

4. Ezoddini AF, Sheikhha MH and Ahmadi H. Prevalence of dental developmental anomalies: A radio- graphic study. Community Dent Health. 2007;24:140-144.

5. De Coster PJ, Marks LA, Martens LC, Huysseune A. Dental agenesis: Genetic and clinical perspectives. J Oral Pathol Med. 2009;38:1-17.

6. Guttal KS, Naikmasur VG, Bhargava P, Bathi RJ. Frequency of Developmental Dental anomalies in Indian population. Eur J Dent. 2010;4(3): 263-9.

7. Dwijendra KS, Parikh V, George SS, Kukkunuru GT, Chowdary GN. Association of dental anomalies with different types of malocclusions in pretreatment orthodontic patients. J Int Oral Health. 2015;7(6):61-64. 
8. Larmour CJ, Mossey PA, Thind BS, Forgie AH, Stirrups DR. Hypodontia - A retrospective review of prevalence and etiology. Part I. Quintessence Int. 2005;36:263-70.

9. Wu CC, Wong RW, Hägg U. A review of hypodontia: The possible etiologies and orthodontic, surgical and restorative treatment options-conventional and futuristic. Hong Kong Dent J. 2007;4:113-21.

10. Pemberton TJ, Das P, Patel PI. Hypodontia: Genetics and future perspectives. Braz J Oral Sci 2005;4:695-709.

11. Yassin SM. Prevalence and distribution of selected dental anomalies among saudi children in Abha, Saudi Arabia. J Clin Exp Dent. 2016 Dec 1;8(5):e485-e490.

12. White, S.C. and Pharoah, M.J. Oral radiology principles and interpretation. 2002, 6th Edition, Mosby, St. Louis.

13. Afify AR, Zawawi KH. The prevalence of dental anomalies in the Western region of Saudi Arabia. ISRN Dent 2012;2012:837270.

14. Aldhorae KA, Altawili ZM, Assiry A, Alqadasi B, AlJawfi KA, Hwaiti H. Prevalence and distribution of dental anomalies among a sample of orthodontic and non-orthodontic patients: A retrospective study. J Int Oral Health. 2019;11:309-17.

15. Baydas B, Oktay H, Metin Dagsuyu I. The effect of heritability on Bolton tooth-size discrepancy. Eur J Orthod. 2005;27:98-102.

16. Rakhshan V. Congenitally missing teeth (hypodontia): A review of the literature concerning the etiology, prevalence, risk factors, patterns and treatment. Dent Res J. 2015;12:1-13.

17. Kirthiga M, Manju M, Praveen R, Umesh W. Prevalence of aberrant dental morphological details in 6-10 year old school children in an Indian population. Contemp Clin Dent. 2005;6(6):175.

18. Peck L, Peck S, Attia Y. Maxillary canine-first premolar transposition, associated dental anomalies and genetic basis. Angle Orthod. 1993;63:99-109.

19. Shapira Y, Kuftinec MM. Maxillary tooth transpositions: characteristic features and accompanying dental anomalies. Am J Orthod Dentofacial Orthop. 2001;119: 127-134.

20. Peck S, Peck L, Kataja M. Mandibular lateral incisor-canine transposition, concomitant dental anomalies, and genetic control. Angle Orthod. 1998;68:455-466.

21. Chattopadhyay A, Srinivas K. Transposition of teeth and genetic etiology. Angle Orthod. 1996;66:147-152.
22. Laptook T, Silling G. Canine transposition - approaches to treatment. J Am Dent Assoc. 1983;107:746-748.

23. Tariq Alswayyed et al. Patterns Of Dental Anomalies In Patients Attending For Orthodontic Treatment In King Abdul- Aziz Medical City, Riyadh Saudi Arabia. Int J Dent \& Oral Heal. 2018;4:2,8-13.

24. Al-Jabaa AH, Aldrees AM. Prevalence of Dental Anomalies in Saudi Orthodontic Patients. J Contemp Dent Pract. 2013;14(4):724-730.

25. Vani NV et al. Prevalence of developmental dental anomalies among adult population of Jazan, Saudi Arabia. The Saudi Journal for Dental Research. 2016;7,29-33.

26. Papadopoulos MA, Chatzoudi M, Kaklamanos EG. Prevalence of tooth transposition. A Meta-Analysis. Angle Orthod. 2010;80:275-285.

27. Hatzoudi M, Papadopoulos MA. Prevalence of tooth transposition in Greek population. Hell Orthod Rev. 2006;9:11-22.

28. Dahl T. The transposition of teeth [in German]. Zahn Mund Kieferheilkd Zentralbl. 1976;64:267-270.

29. Yilmaz HH, Turkkahraman H, Sayin MO. Prevalence of tooth transpositions and associated dental anomalies in a Turkish population. Dentomaxillofac Radiol. 2005;34:32-35.

30. Gupta SP, Rauniyar S. Prevalence and Distribution of Dental Anomalies among Orthodontic Patients of Kathmandu, Nepal. Orthodontic Journal of Nepal. 2019;9(2):23-28.

31. Onyeaso CO, Onyeaso AO. Occlusal/dental anomalies found in a random sample of Nigerian schoolchildren. Oral Health Prev Dent. 2006;4:181-186.

32. Ghassan B. Abdulkareem, Amal H. Abuaffan. Dental anomalies among a sample of Sudanese Orthodontic Patients. Oral Health and Dental Management. 2016;15(4):261-65.

33. Kazanci F, Celikoglu M, Miloglu O, Ceylan I, Kamak H. Frequency and distribution of developmental anomalies in the permanent teeth of a Turkish Orthodontic patients population. Journal of Dental Sciences. 2011;6:82-89.

34. Bass TB. Observations on the misplaced upper canine tooth. Dent Pract Dent Rec. 1967;18:25-33.

35. Grover PS, Lorton L. The incidence of unerupted permanent teeth and related clinical cases. Oral Surg Oral Med Oral Pathol. 1985;59:420-5.

36. Lindauer SJ, Rubenstein LK, Hang WM, Andersen WC, Isaacson RJ. Canine impaction identified early with panoramic radiographs. J Am Dent Assoc. 1992;123(3):91-92, 95-97. 
37. Gupta SK, Saxena P, Jain S, Jain D. Prevalence and distribution of selected developmental dental anomalies in an Indian population. J Oral Sci. 2011;53(2):231-8.

38. Haugland L et al. Prevalence of Dental Anomalies in Norwegian School Children. Open Journal of Stomatology. 2013;3:329-333.

39. Thongudomporn U, Freer TJ. Prevalence of dental anomalies in orthodontic patients. Aust Dent J. 1998;43(6):395398.

40. Tsai SJ, King NM. A catalogue of anomalies and traits of the permanent dentition of southern Chinese. J Clin Pediatr Dent. 1998;22(3):185-194.

41. Graber LW. Congenital absence of teeth: A review with emphasis on inheritance patterns. J Am Dent Assoc. 1978;96:266-75.

42. Galluccio G, Pilotto A. Genetics of dental agenesis: Anterior and posterior area of the arch. Eur Arch Paediatr Dent. 2008;9:41-5.

43. Stockton DW, Das P, Goldenberg M, D'Souza RN, Patel PI. Mutation of PAX9 is associated with oligodontia. Nat Genet. 2000;24:18-9.

44. Frazier-Bowers SA, Guo DC, Cavender A, Xue L, Evans B, King T, et al. A novel mutation in human PAX9 causes molar oligodontia. J Dent Res. 2002;81:129-33.

45. Salem G. Prevalence of selected dental anomalies in Saudi children from Gizan region. Community Dent Oral Epidemiol. 1989;17(3):162-163.

46. Al-Emran S. Prevalence of hypodontia and developmental malformation of permanent teeth in Saudi Arabian schoolchildren. Br J Orthod. 1990;17(2):115-118.

47. Ghaznawi HI, Daas H, Salakon O. A clinical and radiographic survey of selected dental anomalies and conditions in a Saudi Arabian population. Saudi Dental Journal. 1999;11(1):8-13.

48. Celikoglu M, Kazanci F, Miloglu O, Oztek O, Kamak H, Ceylan I. Frequency and characteristic of tooth agenesis among an orthodontic patient population. Med Oral Patol Oral Cir Cucal. 2010;15:e797-801.

49. Sheikhi M, Sadeghi MA, Ghorbanizadeh S. Prevalence of congenitally missing permanent teeth in Iran. Dent Res J (Isfahan). 2012;9(Suppl 1):105-111.

50. Endo T, Ozoe R, Kubota M, Akiyama M, Shimooka S. A survey of hypodontia in Japanese orthodontic patients. Am J Orthod Dentofacial Orthop. 2006;129:29-35 .

51. Polder BJ, Van't Hof MA, Van der Linden FP, KuijpersJagtman AM. A meta-analysis of the prevalence of dental agenesis of permanent teeth. Community Dent Oral Epidemiol. 2004;32:217-26.

52. Grahnén H. Hypodontia in the permanent dentition a clinical and genetical investigation. Odont Rev. 1956;7:1-100.

53. Hua F, He H, Ngan P, Bouzid W. Prevalence of peg-shaped maxillary permanent lateral incisors: A meta-analysis. Am J Orthod Dentofacial Orthop. 2013Jul;144(1):97-109.

54. Zhou J, Zhao Y, Xia C, Jiang L. Periodontitis with hypercementosis: report of a case and discussion of possible aetiologic factors. Aust Dent J. 2012;57(4):511-4.

55. Pinto AS, Carvalho MS, de Farias AL, da Silva Firmino B, da Silva Dias LP, Neto JM, da Silva AM, Castro FA, Costa AL, De Castro Lopes SL. Hypercementosis: Diagnostic imaging by radiograph, cone-beam computed tomography, and magnetic resonance imaging. J Oral Maxillofac Radiol. 2017;5:90-3.

56. Patil SR, Araki K, Yadav N \& Ghani HA. Prevalence of hypercementosis in a Saudi Arabian Population: A cone beam computed tomography study. J Oral Res. 2018; 7(3):94-97.

57. Bürklein S, Jansen S, Schäfer E. Occurrence of hypercementosis in a German population. J Endod. 2012; 38(12):1610-2.

58. Eren Y, Erdal O, Serdar B, Emin K, Enes G. Evaluation of the frequency and characteristics of hypercementosis in the turkish population with cone-beam computed tomography. Niger J Clin Pract. 2017;20(6):724-8.

59. Luke AM et al. Prevalence of Dental Developmental Anomalies in Patients Attending a Faculty of Dentistry in Ajman, United Arab Emirates. Pesq Bras Odontoped Clin Integr. 2017, 17(1):e3751.

60. Jafarzadeh H, Azarpazhooh A, Mayhall JT. Taurodontism: a review of the condition and endodontic treatment challenges. International Endodontic Journal. 2008;41:375-388.

61. AM-G Darwazeh et al. Prevalence of taurodontism in Jordanian dental patients. Dentomaxillofacial Radiology. 1998;27:163-165.

62. Garvey MT, Barry HJ, Blake M. Supernumerary teeth- an overview of classification, diagnosis and management. J Can Dent Assoc. 1999;65(11):612-616.

63. Fardi A, Kondylidou-Sidira A, Bachour Z, Parisis N, Tsirlis A. Incidence of impacted and supernumerary teeth- a radiographic study in a North Greek population. Med Oral Patol Oral Cir Bucal. 2011;16:e56-61. 